\title{
THE QUESTION CONCERNING EMERGENCE: IMPLICATIONS FOR ARTIFICIALITY
}

\author{
S.M.Ali, R.M.Zimmer and C.M.Elstob \\ Brunel University \\ Uxbridge UB8 3PH \\ England (UK) \\ Syed.Mustafa.Ali@brunel.ac.uk
}

\begin{abstract}
This position paper has three parts. In the first part, a brief historical background and various modern formulations of the concept of emergence are presented. A number of problems associated with the concept are identified. One outstanding problem involves the incommensurability of secondary qualities (or phenomenal qualia) with materialist (externalist) ontologies. The intractability of this problem with respect to existing scientific approaches is an indicator of ontological category error, in this case, an attempt to subsume subjectivity into objectivity. In the second part, various attempts at solving the mind-body problem (of which the subjectivity-objectivity issue is a modern incarnation) are investigated and shown to be problematic. It is argued that these problems necessitate reconsidering the metaphysical foundations upon which the concept of emergence is grounded. In the third part, the notion of emergence is reconsidered and a new theory grounded in a synthesis of Heideggerian and Whiteheadian metaphysics is outlined. Finally, the implications of this synthesis for artificing (technology) are briefly considered. It is maintained that "strong" artificiality, the artifactual realization of natural phenomena such as life and mind, is impossible and that this result follows from the essence of artificing. Thus, ontology does not entail technology.
\end{abstract}

KEYWORDS: emergence, category problem, ontology, panexperientialism, artificiality.

\section{THEORIES OF EMERGENCE}

The earliest articulation of the essence of emergence may well be the ancient Greek maxim 'the whole is more than the sum of the parts' and historical links to the notion of self-organization are traceable to the writings of the pre-Socratics Thales and Anaximander. The first serious attempt at investigating the concept of emergence was not made until the middle of the nineteenth century when G.H.Lewes distinguished between resultants and emergents: in the former, the sequence of steps which produce a phenomenon are traceable while in the latter they are not. Lewes could be interpreted as identifying emergence with the epistemological limitations of an observer. In C.L.Morgan's Emergent Evolution (1923), emergence was identified with novelty while J.C.Smuts', writing in Holism and Evolution (1926) identified it with the generation of stable wholes. Samuel Alexander's Space, Time and Deity (1920), in which emergence is identified with the tendency for things to arrange themselves into new patterns which as organized wholes possess new types of structure and properties, provides the basis for information-theoretic and computationalist interpretations of the concept (Baas,93) (Darley,94). Nagel (1961), following Lewes, defines emergence in epistemological terms. This position is consistent with the adoption of a scientific (materialist) metaphysics and reflected in a commitment to ontological reductionism, the view that emergent phenomena do not contradict physical laws and, moreover, are causally determined by such laws. Non-materialistic theories of emergence are rejected a priori on the grounds that "emergents are regarded as spiritual creations emanating from an unknown shadowy world." (Kenyon,41) However, ontological reductionism does not entail epistemological reductionism: for example, Mayr (1982) defines emergence as the appearance of new characteristics in wholes that cannot be deduced from the most complete knowledge of the parts, taken separately or in other partial combinations. 
Similarly, Churchland (1985) defines emergence in terms of the irreducibility of properties associated with a higher level theory to properties associated with components in a lower level theory. Bottomup causation and epistemological non-reductionism are the defining characteristics of most modern theories of emergence, computationalist or otherwise: in support of the former, Langton (1989) defines emergence in terms of a feedback relation between the levels in a dynamical system: local microdynamics cause global macrodynamics while global macrodynamics constrain local microdynamics; in support of the latter, Cariani (1991), who distinguishes three concepts of emergence, viz. computational, thermodynamic and relative-to-a-model, follows Rosen (1985) in identifying emergence with the deviation of system behaviour from an observer's model.

\section{PROBLEMS WITH EMERGENCE}

Despite an a priori commitment to materialism, there are a number of outstanding problems associated with the concept of emergence which can be briefly stated in the form of a list of opposing metaphysical postulates: (1) realism or relativism (Rosen,77); (2) continuity or discreteness (Cariani,91); (3) monism or pluralism (Bunge,69); (4) causality or epiphenomenality (Sperry,76) (Searle,92); (5) determinism or indeterminism (Elstob,84); (6) reversibility or irreversibility (Prigogine,84); (7) computability or noncomputability (Baas,93); (8) closure or openness (Cariani,89) (Ali,96); (9) intrinsicality-extrinsicality (Crutchfield,94). The intrinsicality-extrinsicality issue is particularly interesting since it leads directly to the issue of observation. Crutchfield (1995) defines observation in terms of the embedding of models within endophysical observers, that is, observers existing within a closed physical system or 'universe'. He maintains that extrinsic emergence, in which a phenomenon is identified as emergent by an exophysical observer, that is, an observer outside the system, leads to an infinite regress of observers in much the same way that the collapse of the wave function by an observer in the Schrödinger's Cat gedanken experiment necessitates a second observer to collapse the wave function of the larger system incorporating the first observer and so on. Crutchfield's solution to the regression problem associated with extrinsic emergence is to fold the regress into the system. This leads to a position similar to that of the participatory interpretation of the measurement problem in quantum theory: the universe gives rise to observers who in turn are responsible for collapsing the wave function describing the universe. It is important to note that this concept of observation is objectivist, not merely in the 'weak' epistemological sense implying universal (necessary) as opposed to particular (contingent), but also in the 'strong' ontological sense that implies externality or 'third-personhood'. There are (at least) two related problems with this position: (1) Emergence depends on complexity, complexity on degree of abstraction, and abstraction on the intentionality of an observer/abstractionist. However, in what sense is it meaningful to speak of intentionality (directedness) in the absence of consciousness ? (2) Consciousness is a phenomenon that is subjective, internal, experiential and first-person. How can the external and non-experiential give rise to the internal and experiential ?

Nagel (1974) maintains that those things of which I am conscious, and the ways in which I am conscious of them, determine (or rather, define) what it is like to be me. Those that have consciousness are (or can become) subjects, beings to whom things can be one way or another, beings it is like something to be. Subjects have experiences, feelings, sensations, in short secondary qualities or qualia. Griffin (1988) maintains that subjectivity and objectivity belong to orthogonal ontological categories and that any attempt at deriving the former from the latter will lead to an instance of category error. Moody (1993) defines the latter as "the result of grouping something in a category with other things that are logically dissimilar." (p.31) It is simply the case that subjectivity is irreducible (ontologically, methodologically and epistemologically) to objectivity. Thus, emergence, with its necessary link to observation (Ayala,85) (Cariani,89) (Baas,93), leads directly to the mindbody problem. 


\section{THE MIND-BODY PROBLEM}

The mind-body problem is simply the problem of relating subjective, internal, mental phenomena to objective, external, material phenomena. Various solutions to the problem have been proposed, beginning, perhaps with Descartes' invocation of a 'God-of-the-gaps' maintaining the link (located in the pineal gland within the brain) between the res cogitans or mental substance and the res extensa or material substance. Dualistic theories fall broadly into two categories depending on the way in which the link between mind and matter is viewed: (1) interactionism - mind and matter are causally connected; (2) psychophysical parallelism (Spinoza) - mind and matter are causally disconnected, merely remaining in operational 'harmony' with each other. Aesthetic dissatisfaction with dualism leads to the postulation of two kinds of monism: (1) physicalism (or materialism) and (2) idealism (or mentalism); in the former, matter is ontologically primitive, whereas in the latter, mind is ontologically primordial. Physicalism gives rise to a number of positions ranging from naive identism (in which mental states are held to be identical with brain states) through to behaviourism, functionalism and eliminative materialism, in which mental phenomena are interpreted as either nonexistent, organizationally-contributive to survival, or simply 'folk psychological' respectively. However, all these positions are problematic: identism since it fails to explain the link between mental states and brain states, establishing, at best, a mere correlation between the two orders of phenomena; behaviourism, functionalism and eliminative materialism since subjectivity is rejected outright, thereby reducing human beings to the level of zombies (Searle,92). Idealism is problematic because under a solipsistic interpretation ( $m y$ mind is the only thing that exists) it fails to adequately explain why the subject-object distinction should arise. Consequently, and consistent with a naturalistic interpretation of the phenomenal hierarchy in evolutionary terms, a number of emergentist schemes have been proposed as possible solutions (Harth,93) (Scott,95).

\section{THE EMERGENT THEORY OF MIND}

Proponents of the emergent theory of mind (ETM) such as Searle (1992) maintain that the mind (consciousness) emerges from the body (brain) as a consequence of bottom-up causal neurophysiological processes. The ETM describes the mind-body relation in terms of a two-level systemic hierarchy: the pattern of neuronal 'firings' in the brain (lower, local or substrate level) give rise to mental phenomena including (but not limited to) the subjective experience of consciousness (higher, global, or emergent level). Proponents of the computational ETM go further and assert that the formal aspect of bottom-up causation, viz. the pattern of neuronal activation, provides the necessary and sufficient conditions for the emergence of consciousness. This position, which is grounded in the theory of emergence as formulated by Alexander, is consistent with functionalism and supports the possibility of artificial consciousness. However, Searle (1992) has contested the computationalist isomorphism, "mind is to brain as software is to hardware", on the grounds that three of the terms (brain, software, hardware) are completely definable in objective terms while the fourth term (mind) necessitates description, at least partially, in subjective terms. Assuming biological-naturalism, Searle advances the following homology: brain states are to mental states as molecular behaviour is to liquidity. However, Tallis (1994) has, in turn, contested this position, maintaining that the latter two terms (molecular behaviour and liquidity) are necessarily on the same side of the mind-matter divide: material (objective) if viewed as intrinsic properties of water; mental (subjective) if viewed as different ways of experiencing/observing water. The assumption of bottomup causation, which entails an epiphenomenal view of mind, has been contested by Sperry (1976) who has examined the link between consciousness and causality in connection with an emergentist solution to the mind-body problem. Sperry describes his position as emergentist, functionalist, interactionist, and monistic. Mind, a spatio-temporal pattern of mass-energy, is identified with subjective meaning which is held to be a causally-supervenient emergent property of neurophysiological processes. The view that material-efficient causation constitutes a closed system is rejected; mind is held to functionally constrain the neurophysiological substrate from which it 
emerges. Hence, formal-final causation allows for top-down causation. Sperry follows Polanyi (1967) in defining the formal-final causality of mind in field-theoretic terms, viz. as an autonomous boundary condition eliminating degrees of freedom in the lower-level substrate.

\title{
5. CREATIO EX NIHILO AND EX NIHILO, NIHIL FIT
}

\begin{abstract}
"Strong" (or ontological as contrasted with merely epistemological) emergence necessarily involves creatio ex nihilo, that is, "creation from nothing" since the (field-theoretic) laws governing the behaviour (or determining the properties) of higher level phenomena are non-reducible to the laws governing behaviour at lower phenomenal levels. However, creatio ex nihilo is a problematic concept since if it is held to apply universally then the primordial substrate (matter in materialism and SpaceTime in Alexander's metaphysics) must itself emerge from nothing, interpreted in the sense of pure emptiness or the void. This is so because if matter (or Space-Time) exists then it must partake of Being and under the conventional interpretation of creatio ex nihilo, emergence of Being from nothingness is implied. Additionally, creatio ex nihilo conflicts with an important metaphysical maxim, one which is consistent with the First Law of Thermodynamics, viz. in a closed system, matter/energy is neither created nor destroyed: ex nihilo, nihil fit or "from nothing, nothing comes". This concept can be broadened into the assertion "like from categorial like". Thus, material phenomena can give rise to material phenomena (of lesser or greater complexity since the maxim does not exclude the possibility of evolution) and mental phenomena can give rise to other (lower or higher order) mental phenomena. If experience (or subjectivity) is categorial, that is, ontological, then it cannot be reduced to the non-experiential (or objective). However, this is precisely what is being asserted in the ETM. Hence, the categorial mind-body problem of secondary qualities or qualia again arises in the context of emergentism. Given the apparent intractability of this problem, it is worth re-examining its status; in short, is the mind-body problem a well-formed problem in the sense of logically sound? Ryle (1949) has argued that "the belief that there is a polar opposition between Mind and Matter is the belief that they are terms of the same logical type" (p.23), a belief which he holds to be false given his rejection of Cartesian substance dualism and assertion that mind is an aspect or property of matter. However, while it is certainly the case that Cartesian substance dualism is problematic (two ontologically different substances cannot interact given the closure of each to the other and the validity of the extended form of the above maxim) and hence, the associated category problem does not emerge as well-formed, this does not apply to the subjectivity-objectivity problem (Griffin,88). While it may be incorrect to maintain a polar opposition between mind and matter on the basis of logical type identity, subjectivity and objectivity are instances of a more general logical type, viz. perspective or view (Nagel,86). Subjectivity is an epistemological perspective which is both ontologically grounded and ontically irreducible; in short, subjectivity cannot be generated from objectivity since they are mutually exclusive categories.
\end{abstract}

It would appear, therefore, that the only possible solution to the mind-body problem which does not entail a category error (a violation of the preceding maxim under its extended formulation) is some form of dual-aspect theory such as "panpsychism" in which the most primitive ontological components in the universe are held to possess both internal (subjective) and external (objective) aspects (Nagel,86). However, panpsychism (or animism) conflicts with some of our most basic assumptions regarding the problem of other-minds, viz. the problem of determining whether or not any entities other than myself possess minds: although the ascription of consciousness on the basis of external behaviour alone is problematic (Searle,80), surely there is some connection between consciousness and external behaviour? A denial of this position would entail holding that entities such as stones, clouds and, perhaps more controversially, computers are conscious. What is required is an emergentist variant of panpsychism which (1) supports the ontological irreducibility of subjectivity (thereby solving the mind-body problem) and (2) is consistent with a phenomenal hierarchy in which matter, life and mind are viewed as qualitatively distinct from an objective, 
behaviouristic perspective (thereby preventing conflict with the intuitive requirement for inclusion of behavioural criteria in the solution of the other-minds problem.)

\title{
6. HEIDEGGER AND THE QUESTION OF BEING
}

In preparation for the discussion in the next section, it is necessary to consider what is meant by Being in the context of Western metaphysics. The philosophy of Martin Heidegger (1889-1976) is the result of a detailed questioning concerning Being and hence, provides an appropriate starting point. For example, in the introduction to The End of Philosophy (1973), Stambaugh maintains that

\begin{abstract}
with Plato's distinction of essence (whatness) and existence (thatness), the difference between Being and beings [or things] is obscured, and Being as such is thought exclusively in terms of its relation to beings as their first cause .. and thus itself as the highest of those beings.

When the distinction of essence and existence arises, it is essence, whatness, which takes priority. The priority of essence over existence leads to an emphasis on beings. The original meaning of existence as physis, originating, arising, presencing, is lost, and existence is thought only in contrast to essence as what 'factually' exists. In contrast to what 'factually' exists here and now, Being is set up as permanent presence (nominal) abstracted from presencing (verbal) in terms of time-space. (p.x)
\end{abstract}

Thus, metaphysics since Plato has concentrated on the essence of beings, interpreting this essence in terms of categorial notions, for example, space, time, substance, process, change, cause, whole, part, quantity etc. The Being of beings, however, has been reduced to the status of a mere universal predicate and defined as existence, thatness, actuality or reality. However, according to Heidegger (1973), "in the beginning of its history, Being opens itself out as emerging (physis) and unconcealment (alētheia). From there it reaches the formulation of presence and permanence in the sense of enduring (ousia). Metaphysics proper begins with this." (p.4) From this assertion it follows that the Platonic interpretation of Being is grounded in a more primal mode of Being, viz. alètheiaphysis or emergent presencing in what is unconcealed (beings). Consequently, Heidegger maintains that "the actual being, is incomprehensible in its beingness [or Being] when thought in terms of idea [whatness or essence]." (p.9) Furthermore, "because thatness remains unquestioned everywhere in its nature, not, however, with regard to actual beings (whether they are or are not), the unified essence of Being, Being as the unity of whatness and thatness, also determines itself tacitly from what is unquestioned." (p.11) By revealing a more originary mode of Being other than that of pure thatness, Heidegger raises the possibility of a hermeneutic (interpretative) approach in which Being is seen to disclose itself multiply. Dreyfus (1991) claims that the basis for this approach is already implicit in the thought of Aristotle:

\footnotetext{
'Being' does not behave like a very general predicate. For example, the Being of numbers seems not to be the same as, but at best only analogous to, the Being of objects, and the Being of real objects differs from the Being of imaginary objects such as unicorns. Aristotle says that Being is predicated analogously. Since Being transcends the universality of a class or genus the Scholastics called it a transcendens. Heidegger concludes that Being is clearly no ordinary predicate. (p.10)
}

Dreyfus maintains that Being is "'that on the basis of which beings are already understood'. Being is not a substance, a process, an event, or anything that we normally come across; rather, it is a fundamental aspect of entities, viz. their intelligibility." (p.xi) In Being and Time (1927), Heidegger began a detailed investigation of the structure of Being beginning with that being on the basis of which all beings gain their intelligibility, viz. human being. Heidegger's approach to the understanding of Being is phenomenological (ontological, existential, hermeneutic) and thereby distinct from the scientific approach which is causal (ontical). Four areas of investigation are possible depending on the kind of investigation (ontical or ontological) and what is being investigated (a 'who' or a 'what'). Thus, ontologically, there are two main categories of Being: (1) human being or Dasein and (2) non-human being. The latter can be categorized into the ready-to-hand (Zuhandenheit) 
and the present-at-hand (Vorhandenheit). Dasein (being-there, that opening or hermeneutic clearing which enables Being to come forth from concealment) is ontically distinct from non-human being in that it has the understanding of Being as its unique characteristic. This understanding is either (1) preontological (pretheoretical) or (2) ontological; in the former, understanding takes the form of tacit and ineffable know-how which assumes a 'Background' of shared practices, skills etc, while in the latter it takes the form of reflective know-that (or know-what) characteristic of the kind of understanding usually associated with a conscious cognitive subject. Dasein is a being-in-the-world where the 'in' of being-in should be understood in terms of concernful involvement (for example, 'being in love') and not spatial location (for example, 'being in a box'). The ready-to-hand (or available) is how Dasein encounters non-human being when coping with the world in an averageeveryday unreflective manner. The ready-to-hand is something which is used in-order-to get something done and is, therefore, defined in terms of its functionality with respect to the concerns (unreflective purposes) of Dasein. However, as Dreyfus (1991) states, "an 'item' of equipment is what it is only insofar as it refers to other equipment and so fits in a certain way into an 'equipmental whole'." (p.62) The equipmental whole may be distinguished from other 'wholes' such as the referential and involvement whole as follows: the equipmental whole describes the interrelated equipment; the referential whole its interrelations; and the involvement whole human purposiveness which is defined in terms of significance, "the background upon which entities can make sense and activities can have a point." (p.97) Heidegger elucidates the meaning of the ready-to-hand by way of an example, that of a person engaged in the act of hammering: if all is going well and the nail is being driven into the wood, then hammer, nail and wood are all transparent to the one doing the hammering, forming part of the functional network of equipment. The present-at-hand (or occurrent), encountered by Dasein in its mode of the Cartesian subject reflecting upon objects, describes beings (things) viewed independently of functional context, significance or the equipmental whole, and hence, independently of their relationship to Dasein. When the ready-to-hand becomes the present-athand (for example, during 'breakdown') it is revealed as an object with determinate, context-free properties. Dreyfus maintains that Heidegger "wants to stress three points. (1) It is necessary to get beyond our practical concerns in order to be able to encounter mere objects. (2) The 'bare facts' related by scientific laws are isolated by a special activity of selective seeing rather than being simply found. (3) Scientifically relevant 'facts' are not merely removed from their context by selective seeing; they are theory-laden, i.e. recontextualized in a new projection [emphasis added]." (p.81) The transition from a concerned being-in-the-world to a subject reflecting upon objects emerging during breakdown lends support to Heidegger's contention that the primordial mode of Dasein is the unreflective or pre-ontological mode:

Heidegger does not deny that we sometimes experience ourselves as conscious subjects relating to objects by way of intentional states such as desires, beliefs, perceptions, intentions, etc., but he thinks of this as a derivative and intermittent condition that presupposes a more fundamental way of being-in-the-world that cannot be understood in subject/object terms. (p.5)

However, what is also thereby asserted is the primacy of the functionally-contextual nature of the equipmental whole:

For Heidegger, unlike Descartes, Husserl, and Sartre, the object of mere staring, instead of being that which really is, is an impoverished residue of the equipment we directly manipulate. The bare objects of pure disinterested perception are not basic things we can subsequently use, but the debris of our everyday practical world left over when we inhibit action. (p.47)

Hence, Heidegger maintains that the ready-to-hand is a more primordial way for things to be than the present-at-hand. However, he should not be understood as merely asserting the primacy of the practical (praxis) over the theoretical (theoria). As Dreyfus (1991) states, "Heidegger seeks to supplant the tradition by showing that the ways of Being of equipment and substances [objects with context-free properties], and of actors and contemplators [Cartesian subjects], presuppose a 
There are two stages in the development of Heidegger's phenomenology, the latter of which is signalled by 'the turn' (Die Kehre), when Heidegger shifts his attention from a hermeneutic of Dasein to historical thinking on Being (Sein). The distinction between the two stages may be introduced by way of a statement due to Dreyfus explicating the thought of the Heidegger of Being and Time: "for Heidegger, scientific theory is an autonomous stance. It is not mere curiosity, nor is it merely based on an interest in control [emphasis added]." (p.80) This position conflicts with the account of science given in (Heidegger,77), a post-Kehre work in which science is linked to technology which in turn is linked to Enframing (das Gestell), a mode of Being which developed out of Greek techne (artificing). Heidegger maintains that it is with Plato and Aristotle that techne begins to take on the form of Enframing following the bifurcation of Being into essentia (whatness) and existentia (thatness). As stated previously, the pre-Socratics had a very different understanding of technē, a consequence of their very different understanding of Being as alettheia-physis or the emerging power which brings itself forth from concealment. The thinking of the later Heidegger concentrates on two related projects: firstly, a more aesthetic and poetic approach to the understanding of Being (Heidegger,71), and secondly, an attempt at clarifying the nature of logic and science in order to draw attention to the 'danger' inherent within technology (Heidegger,77). Of particular relevance in the context of this investigation is his understanding of mathematics:

mathematics is the reckoning that, everywhere by means of equations, has set up as the goal of its expectation the harmonizing of all relations of order, and that therefore 'reckons' in advance with one fundamental equation for all possible ordering [emphasis added]. (p.170)

By this, Heidegger means to imply that mathematics and modern science (which is mathematical) are self-fulfilling in the sense that both specify a priori what and how things are to be encountered, viz. as the Enframed (or anthropically-ordered), a characteristic of the fact that science and mathematics have their metaphysical origins in techne. . Heidegger maintains that although the Enframing characteristic of modern theoretical science is $a$ way of revealing Being, it does not constitute the way of revealing Being; hence, his commitment to hermeneutic realism:

\begin{abstract}
Theory never outstrips nature - nature that is already presencing - and in this sense theory never makes its way around nature. Physics may well represent the most general and pervasive lawfulness of nature in terms of the identity of matter and energy; and what is represented by physics is indeed nature itself, but undeniably, it is only nature as the object-area whose objectness is first defined and determined through the refining that is characteristic of physics and is expressly set forth in that refining. Nature, in its objectness for modern physical science, is only one way in which what presences - which from of old has been named physis - reveals itself and sets itself in position for the refining characteristic of science .. Nature thus remains for the science of physics that which cannot be gotten around. (pp.173174)
\end{abstract}

Importantly, he states that

scientific representation, for its part, can never decide whether nature, through its objectness, does not rather withdraw itself than bring to appearance the hidden fullness of its coming to presence. Science cannot even ask this question, for, as theory, it has already undertaken to deal with the area circumscribed by objectness. (p.174)

In this statement, Heidegger maintains that scientific objectivity prevents the unconcealment, appearance or emergence of other ways (modes) of Being. Thus, the scientific interpretation of emergence is clearly very different from Heidegger's interpretation: on the former, emergence denotes the appearance of new properties in a whole that are not present in any of its parts; on the latter, emergence denotes the unconcealment of the various modes of Being in beings. Appreciation of this distinction is crucial for the following reasons: firstly, on the Heideggerian view, consciousness is not held to be emergent in the sense understood by Searle (1992); that is, consciousness is not a systemic whole constructed from parts, a view which ultimately leads to the category problem 
described in $\$ 5$ if materialism is assumed. Rather, consciousness (subjectivity) is a mode of Being which is revealed, that is, brought forth from concealment. The value of Heidegger's understanding of emergence is three-fold: (1) it is originary, dealing with the understanding of the emergence of Being as opposed to merely beings (\$7); (2) it solves the category problem by unconcealing an alternative ontology (\$8); and (3) it enables the creatio ex nihilo and ex nihilo, nihil fit maxims to be rendered commensurable ( 9 ). Secondly, Heidegger's clarification of the distinction between the two modes of poiessis or coming-forth (\$7) has a number of implications for the "strong" artificiality project, that is the artifactual realization of natural phenomena, as discussed in $\S 10$.

\section{PROLEGOMENON TO A NEW THEORY OF EMERGENCE}

It can be argued that the apparent incommensurability of emergentist ( $\$ 4)$ and panpsychist ( $\$ 5)$ accounts is a consequence of adopting a monistic, materialistic, and atomistic metaphysics. Etymological analysis of the notion of emergence reveals an alternative and historically antecedent interpretation of the concept (briefly introduced in §6) which renders the positions commensurable. The Oxford Latin Dictionary (1982) provides the following etymology for emergence:

emergo gere 2. to come forth (from confinement, concealment), emerge. 4. to become apparent, come to light; (of something unexpected) to turn up, present itself, to appear as a result, to emanate.

Adopting the hermeneutic approach to philosophical investigation pioneered by Heidegger and questioning concerning emergence reveals two types of emergence:

1. emergence $_{1}:$ a movement between Being and beings

2. emergence $_{2}$ : a movement between parts (beings) and wholes (beings)

(1) is associated with the coming-into-being (or becoming) of ontical or ontological primitives from a poietic (generative) source while (2) is associated with the manifestation of categorial potentialities in complexes once ontical or ontological primitives have been defined. Heidegger's ontological analysis of Being (1959) leads to a conception of emergence in terms of the poiessis or coming-forth from concealment of Being in beings (things, essents). As stated in $\S 6$, Being is neither substance nor process; rather, it is the originary 'background' condition for the intelligibility of beings (Dreyfus,91). (Hence, Heidegger's radical assertion that the positions of Heraclitus, a processist, and Parminides, a substantialist, are equivalent.) Being is not to be thought of in terms of a whole (system or complex) composed from parts (components or primitives); rather, Being is the primordial ground of parts and wholes, in fact, of all that is. Hence, the following statement due to Heidegger (1959), originally formulated in the context of a critique of anthropological thought:

\footnotetext{
The beginning is the strangest and the mightiest. What comes afterward is not development but the flattening that results from mere spreading out; it is inability to retain the beginning; the beginning is emasculated and exaggerated into a caricature of greatness taken as purely numerical and quantitative size and extension. That strangest of beings [man] is what he is because he harbours such a beginning in which everything all at once burst from superabundance into the overpowering and strove to master it. (p.155)
}

Heidegger (1977) distinguishes two forms of poiessis (coming forth) in Greek thought: physis (autopoiessis or bringing-forth-by-self) and techne (allopoiēsis or bringing-forth-by-other) corresponding to the modes of becoming associated with naturals and artifactuals (or artifacts) respectively. In this section, the presentation focuses entirely on physis, the 'self-cutting' originary power of Being, which establishes emergence ${ }_{1}$ as a necessary condition for emergence $_{2}$. There are four possibilities for emergence delimited by type (emergence or $_{1}$ emergence $_{2}$ ) and direction (expansive or contractive) as shown in Table 1: 


\begin{tabular}{|c|c|c|}
\hline & emergence $_{1}$ & emergence $_{2}$ \\
\hline Expansive & joining $_{1}$ : essent $_{\text {part }} \rightarrow$ Being & joining $_{2}:$ essent $_{\text {part }} \rightarrow$ essent $_{\text {whole }}$ \\
\hline Contractive & cutting $_{1}:$ Being $\rightarrow$ essent $_{\text {part }}$ & cutting $_{2}:$ essent $_{\text {whole }} \rightarrow$ essent $_{\text {part }}$ \\
\hline
\end{tabular}

Table 1 Four possibilities for emergence.

An originary joining of type joining ${ }_{1}$ is necessitated in the event of category error (a form of 'breakdown'); this originary joining corresponds to the disappearing of existing ontical or ontological primitives (concealment of Being) and the appearing of new ontical or ontological primitives (unconcealment of Being). The hermeneutic (interpretative) movement takes the form of a spiral as shown in Fig.1:

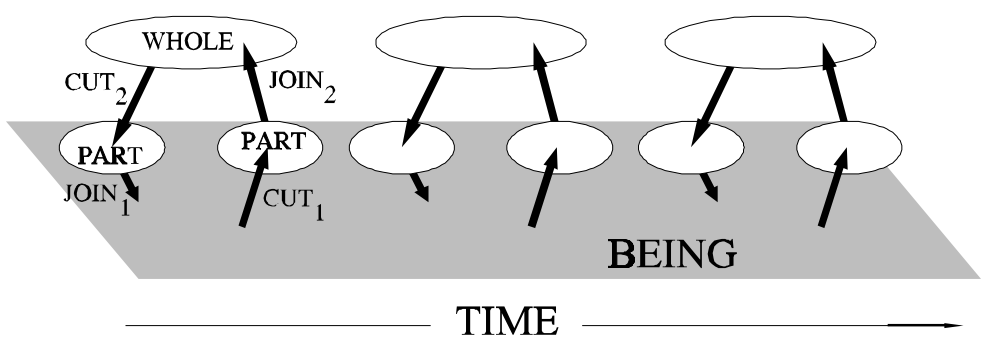

Figure 1 The hermeneutic spiral.

The stages in the hermeneutic spiral associated with materialism are as follows: (1) objective, external atoms (parts) unconcealed as ontical primitives ( cutting $\left._{1}\right) ;(2)$ objective physical-biological systems emerge from atomic substrate (joining 2 ); (3) subjective (experiential) biological systems encountered leading to category problem (ontical-breakdown); (4) category problem traced to ontical primitives $\left(\right.$ cutting $\left._{2}\right)$; (5) ontical primitives withdraw into concealment (joining $)_{1}$. The problem of onticalbreakdown associated with materialism can be solved if the manifoldness of Being and its unconcealment in various modalities is accepted. As stated in §6, Heidegger's questioning was motivated by an attempt at revealing the structure of Being via phenomenological (hermeneutic) investigation of the structure of a particular kind of Being, viz. Dasein or human being. However, in unconcealing two ways of being human (causal or ontical and existential or ontological), Heidegger also reveals two modes of Being and in revealing the manifoldness of Being, Heidegger implicitly points toward the possibility of a post-materialistic metaphysics. Heidegger's denial of the ontological primacy of subjective, reflective (thematic) consciousness with respect to human being (Dasein) does not entail support for the view that objects are ontically primitive and subjects ontically derivative nor that Being (as the ground of beings) is ontically objective; according to Heidegger, it is the dualism of subjects and objects that is secondary, emerging in the event of ontologicalbreakdown. However, the ontical question of the emergence of subjectivity, that is, the category problem described in $\S 2$, remains unsolved. In order to solve this problem, it is necessary to consider an alternative metaphysics rather than an alternative phenomenology; however, this is only possible because, by way of phenomenology, it has been shown that Being has manifold modes and hence, can support a metaphysical paradigm-shift. It was argued in $\$ 6$ that Being conceals consciousness, that consciousness is not created ex nihilo in the sense of "from void"; rather it is revealed. Subjectivity is, therefore, a mode of Being awaiting unconcealment through the hermeneutic process. Heidegger maintains that subjects and objects emerge from being-in-the-world. This position is consistent with Whiteheadian organicism (panexperientialism) in which subjectivity and objectivity refer to different temporal aspects of experiential events. Thus, an ontical solution to the category problem is to be found in the coming forth from concealment of Whiteheadian events as newly emerging ontical primitives ( cutting $_{1}$ ). 


\section{PANEXPERIENTIALISM}

Materialism is based on the metaphysical assumption of vacuous actuality in which the ultimate ontical primitives of reality are held to be non-experiential and non-spontaneous. However, as Griffin (1997) states,

we know from our own experience that experiencing actualities can exist, but we have no experiential knowledge that a vacuous actuality is even possible. (p.4)

Additionally, realism has been conflated with materialism (objectivism) in the philosophy of Descartes, Galileo and Newton. Both Heidegger and Whitehead are committed to realism; however, in the former, this realism is hermeneutic (ontological) while in the latter it is processual (ontical). Griffin (1997) maintains that "panexperientialist physicalism portrays the world as comprised of creative, experiential, physical-mental events." (p.13) An event (actual occasion or actual entity) is a happening at a certain place at a certain time. A process is a series or chain of events which can give rise to either (1) a concresence (compound individual or organism), that is, a complex and highly ordered society of events manifesting both experience and causation or (2) an aggregate in which the experiential and causal components associated with primitive components cancel out in the whole. (A compound individual is a nexus, a system of internally-related interacting subjects whereas an aggregate is a network, a system of externally-related interacting objects. Internal relations are constitutive of both the essence and existence of things; hence, panexperientialism - a form of idealism - is a priori committed to the bifurcation of Being described in §6.) Experience implies subjectivity, which pan-experientialists associate with "for-itself" in contrast to mere "what-it-islikeness" (\$2), and is defined in terms of both (1) prehension and (2) causation. Farleigh (1996) maintains that "to 'prehend' an object [datum] is to experience it, perceive it, feel it, or more literally, to grasp it or take it into account, though not necessarily in a conscious way." (p.7) Prehension is of both past and external events and is involved in determining the creative causal response of an event to incoming efficient causation. As stated previously, each event has both physical and mental aspects. The physical aspect is always prior and is the reception by the event of the efficient causation of prior events into itself. As Griffin (1997) states: "each event prehends aspects of the past into itself and then gets aspects of itself prehended into future events." (p.15) Again,

Every unit [or compound-individual] event (as distinct from an aggregational event) has a mental aspect, and this mentality involves an element, however slight in the most elementary events, of spontaneity or self-determination. Although the event's physical [aspect] is given to it, its mentality is its capacity to decide precisely what to make of its given foundation. Its physicality is its relation to past actuality; its mentality involves its prehension of ideality or possibility, through which it escapes total determination by the past. (p.13)

Hence, events are experiential both as subjects (caused) and objects or superjects (causing). Furthermore, "as subjects, events enjoy an inner duration; as objects, however, they are purely spatial. An event cannot be prehended until its moment of subjectivity is finished, because it is nothing fully determinate until its moment of self-determination is completed." (p.15) Thus, instantaneous events are fictions on Whiteheadian panexperientialism. The distinction between Newtonian (necessary) and Whiteheadian (contingent) events is shown in Figs. 2 and 3 respectively:

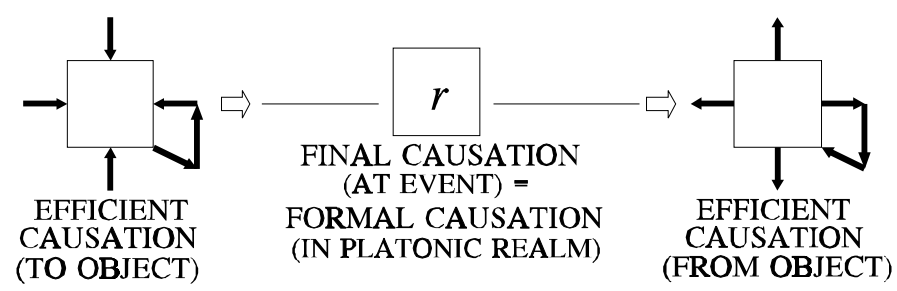

Figure 2 A Newtonian event ( $r$ denotes the response). 


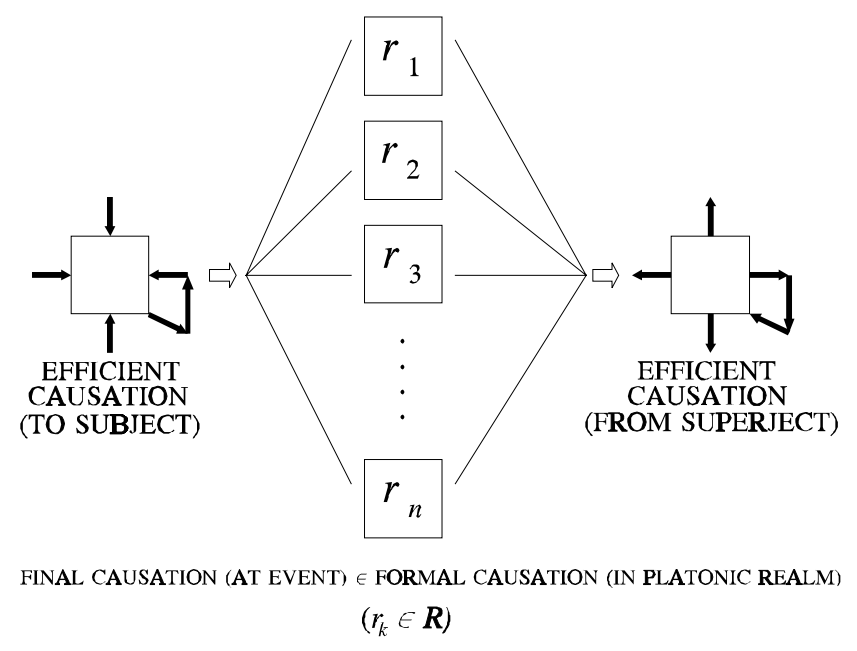

Figure 3 A Whiteheadian event.

Although panexperientialists hold that experience is ontically primitive, this does not entail the panpsychist claim that consciousness is primordial. Consciousness is not identical to experience since the former involves the capacity for negation, that is, making a distinction between possibility and actuality. As Griffin (1997) states,

very elementary events, by virtue of synthesizing prior events and possibilities into rudimentary analogues to propositions, have incipient-intentionality; somewhat higher-level events, complex enough to form propositions, have proto-intentionality; while only very high-level events are sophisticated enough to contrast propositions with alternative possibilities, thereby enjoying .. the subjective form of consciousness." (pp.13-14)

Hence, panexperientialism is consistent with non-materialistic emergentism and the Greek view of reality in which subjectivity is held to be intrinsic to nature $(\$ 10)$. However, while this metaphysics solves the category problem, it appears to do so at the expense of the structural order of the world. This is entailed by postulating 'freedom', that is, the subjective response of an event to incoming causation, as real since universal causation (necessity, determinism) is thereby undermined. If panexperientialism is to be retained, it must, therefore, explain the stability of phenomena. Whitehead is able to achieve this by incorporating a Platonic component into his framework, viz. the idea of ingression, that is, the realization of the potentiality of 'eternal objects' (Platonic forms) in actual entities (events). Although in the Whiteheadian universe all events are connected, the extent of connection varies; hence, certain events participate in the determination of an event to a greater extent than other events. The extent of participation in an event is determined by three factors: (1) incoming efficient causation; (2) ingression of eternal objects; and (3) the subjective response of the event, that is, a selection of which eternal objects (from a given set) are to ingress (structurally supervene) on the incoming efficient causes. Eternal objects act as a transcendent source of stability. Hence, as Griffin (1997) states, "the regularities of nature are not due to externally imposed 'laws' but are .. nature's most long-standing habits - the habits of its most elementary members, reflecting patterns that they have internalized." (p.16) For example, "the electron in the living human body .. will behave differently than it did in the organic environment, not because the 'laws of electron behaviour' have been violated, but because it is there subject to different influences." (p.17) Thus, determinism is the exception, not the rule. However, Collingwood (1945) is critical of the idea of eternal objects. He maintains that

a world of eternal forms which included in itself forms of every empirical detail in nature would only be a lumberroom of natural details converted into rigid concepts, and that a world of forms so conceived, instead of explaining the processes of nature, would be a mere replica of these processes themselves with the process left out. [Thus,] appealing to the conception of a world of forms or objects as the source or ground of natural process [necessitates] an account of this world .. (pp.171-172) 
Thus, Whiteheadian panexperientialism contains the potential for vicious infinite regress. It is argued that these problems are artifacts of the Platonic essence(potentiality)-existence(actuality) duality. Plato maintains a distinction between the realm of existence (matter or substance) and the realm of subsistence (ideas or forms). However, if subsistents (forms) are then they must partake of Being. Hence, the solution to the problem of infinite regress lies in transcending the opposing categories to the more primordial ground of pure Being understood as presencing forth from concealment. The link between Cartesian, Whiteheadian and Heideggerian frameworks with respect to the issue of structural stability is shown in Table 2:

\begin{tabular}{|c|c|c|c|}
\cline { 2 - 4 } \multicolumn{1}{c|}{} & Descartes & Whitehead & Heidegger \\
\hline $\begin{array}{c}\text { a priori } \\
\text { (substrate) }\end{array}$ & Laws & Forms & Physis \\
\hline $\begin{array}{c}\text { a posteriori } \\
\text { (emergent) }\end{array}$ & Phenomena & Laws & Forms \\
\hline
\end{tabular}

Table 2 Structural stability in Descartes, Whitehead and Heidegger.

Farleigh (1996) maintains that

dualism is strongly rejected and, for Whitehead, this means that epistemology does not have any priority over ontology. Any inquiry into knowing is at the same time an inquiry into being. (p.3)

The latter view is correct insofar as knowing is a mode of Being. However, Being subsumes knowing; hence, the reverse of Farleigh's position, viz. "any inquiry into being is at the same time an inquiry into knowing" is false. This view is consistent with Heidegger's critique of Husserlian phenomenology in which human being is equated with the experiencing Cartesian ego. Hence, although Whiteheadian panexperientialism solves the category problem, its situatedness within Being as an encompassed mode (or way) must not be ignored if the question of Being is to remain valid.

\section{THE EX NIHILO REVISITED}

Contrary to Bunge's (1977) assertion that he regards nothingness as an entity, Heidegger (1993) maintains that "the nothing comes forward neither for itself nor next to beings, to which it would, as it were, adhere." However, he goes on to state that "for human existence, the nothing makes possible the openedness of beings as such. The nothing does not merely serve as the counterconcept of beings; rather, it originally belongs to their essential unfolding as such. In the Being of beings the nihilation of the nothing occurs." (p.104) Heidegger clarifies the latter statement as follows: "in its nihilation the nothing directs us precisely towards beings." (p.104); furthermore, "negation is grounded in the not that springs from the nihilation of the nothing." (p.105) Thus, according to Heidegger, the nihilation of the nothing is the poietic source of negation and as Spencer-Brown (1969) has shown, negation is equivalent to the act of drawing a distinction. Heraclitus maintained that conflict (setting-apart) is the source of both the creation and preservation of the world, anticipating Spencer-Brown's assertion that a universe comes into being when a space is severed. The link is clear: conflict necessitates difference and difference implies distinction. Hence, the nihilating nothing is the source of beings. This is readily shown: nihilation of nothing $=$ not nothing $=$ not notthing $=$ thing $=$ being; hence, nihilation of nothing $=$ being. However, the making of a distinction necessitates a distinction-maker. If the nothing is the ground of distinction-making, it must have the capacity for both making (acting) distinctions and recognizing (knowing) that distinctions have been made, both of which are modes of Being. In $\S 6$ it was stated that Being is the poietic source of beings since Being discloses (unconceals, reveals) itself in and as beings. Hence, Being=Nothing. 
This interpretation finds support in the statement that "the nothing does not remain the indeterminate opposite of beings but reveals itself as belonging to the Being of beings" (p.108), a position consistent with Hegel's assertion that pure Being and pure Nothing are the same. Being in concealment is identical to the nothing and its unconcealment in beings corresponds to the nihilation of the nothing. According to Heidegger, the why of unconcealment is "enigmatic". However, in the context of this study it can be linked to the (re-)emergence of the question of Being, that is, to a recognition of the necessity of a hermeneutic approach to revealing the various modes of Being. In asserting that the nothing is not identical to the void (the latter is a fiction of conventional metaphysical discourse), but rather is the poiettic ground of beings, Heidegger is able to correct the conventional (mis)interpretation of ex nihilo, nihil fit, viz. "nothing comes from nothing". The corrected version is "from nothing, nothing comes to be", that is (Being=nothing) $\rightarrow$ beings. Thus, creatio ex nihilo because ex nihilo, nihil fit and the positions are rendered commensurable. This might appear to support a solution to the category problem (\$5) based on an expansive (joining) form of emergence $_{2}$. However, this inference is incorrect: subjectivity as a mode of Being associated with certain kinds of beings is concealed-within Being awaiting unconcealment in beings. (It is important to appreciate that the primordial condition of Being is concealment.) Hence, the category problem can be solved, but only by moving to an interpretation of Being (an alternative ontology) in which subjectivity and objectivity are irreducible essents (modes of Being). As argued in the previous section, panexperientialism provides such an interpretation. Thus, emergentism is possible, but only if the concept of emergence is extended to incorporate emergence $_{1}$.

\section{THE ESSENCE OF ARTIFICING}

In $\S 7$, a distinction was made between the two modes of poiessis (emergence or coming-forth), viz. physis (or autopoiēsis) and technē (or allopoiēsis), and in $\S 8$, a (post-materialist) ontology for physis based on panexperientialism was briefly described. In this section, the meaning of techne will be investigated. For the Greeks, poiessis was the gathering of man into the presencing of subjects (beings); techne was a mode of artificing (artifact-making) in which man was summoned-forth as the means by which artifacts were brought forth into Being from concealment (Heidegger,77). On this original interpretation of poiessis both man and artifacts are viewed as hermeneutically integral components of the self-presencing of Being (physis); hence, there is no trace of "design for human purposes" (anthropocentricity) or "ideas in the mind awaiting realization" (egocentricity) associated with the artificing (techne $\bar{e}$ ) of the Greeks. However, modern alētheuein (revealing) is radically different; according to Heidegger, it is a challenging-forth by subjects (volitional Cartesian egos) setting-upon objects (beings) which are re-conceived as standing-reserve (Bestand), that is, as resources 'Enframed' or ordered (set in order) according to human purposes. Although Heidegger draws a distinction between poiessis and Enframing (das Gestell), the latter can be viewed as a type of the former in which the determining locus (subject) has been inverted (Fig.4):

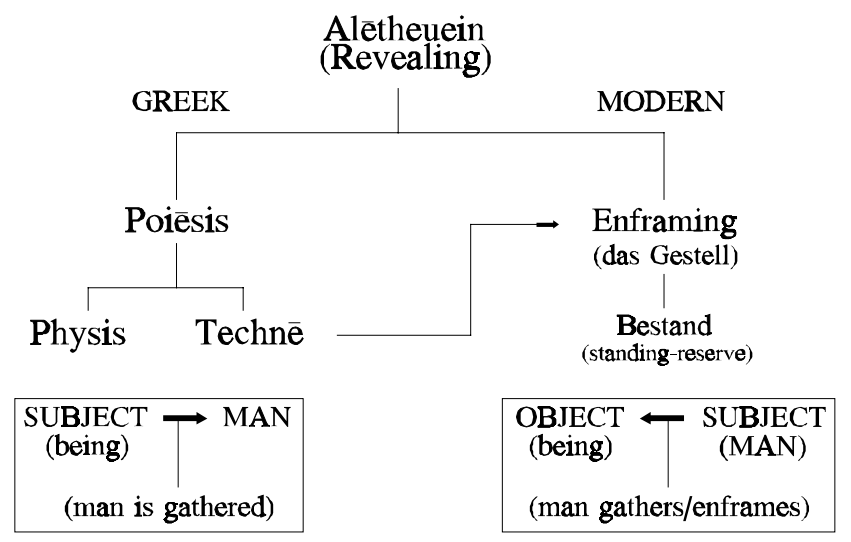

Figure 4 The subject in poiessis and Enframing. 
The essence of modern techne, that is, artificing in its modern incarnation as Enframing is described by Heidegger (1977) as follows:

What is, in its entirety, is now taken in such a way that it first is in being and only is in being to the extent that it is set up by man, who represents and sets forth .. The Being of whatever is, is sought and found in the representedness of the latter. (pp.129-130)

The distinction between Greek and modern artificing can be understood in terms of the shift in meaning of the maxim, "man is the measure of all things": For Protagoras, to whom first articulation of the statement is attributed, it meant that finite man is a limiting horizon for the unconcealment of Being (in beings); that is, Being is revealed to man only partially at any time, a position which is consistent with hermeneutic realism. However, with Descartes the maxim came to mean the selfcertainty of the ego upon which the Being of beings is grounded. In the egocentricity of the Cartesian 'cut' (Enframing), man at once both (1) blocks the presencing of Being as physis and (2) forces the presencing of Being as standing-reserve. There are (at least) two consequences of the shift in the locus of subjectivity and the change in the orientation of man to beings in the move from poiesis to Enframing (das Gestell) which can be identified as (1) ontological and (2) ontical.

\subsection{Ontological}

According to Heidegger, concernful, non-thematic, involved being-in-the-world is the primordial mode of human being; the primordial Being of the world is, therefore, equipmental, that is, ready-tohand or available (§6). As Dreyfus (1991) states, "equipment is defined by its function (in-order-to) in a referential whole" (p.91) which, in turn, is determined relative to an involvement (meaning or significance) whole. Furthermore,

since equipment is in no way derivative, and since involvement is as genuine a mode of access as theory, we can say that equipment in use is equipment as it is in itself. (p.66)

Consequently,

traditional ontology [that is, the metaphysics of ontical causality] succeeds only if it can account for all modes of being, including Dasein's practical activity and the equipmental whole in which Dasein is absorbed, in terms of the law-like or rule-like combinations of occurrent elements. If it can be shown that the world is irreducible to occurrent elements, be they bits of matter, atomic facts, sense data, or bits of information, then an ontology based on the occurrent fails. (pp.108-109)

Heidegger maintains that the ontological (existential) cannot be derived from the ontical (causal). Evidence supporting this claim includes Husserl's failed attempt at articulating the structure of the human life-world and the frame problem of artificial intelligence (the problem of extracting contextually-relevant knowledge from an ever-expanding factual repository). Although, Heidegger accepts that the ontical is in some sense prior to the ontological since, for example, the properties of materials constrain the functionality of equipment, the ontical cannot be made intelligible without the ontological. Since Being denotes intelligibility (\$6), the Being of beings is fundamentally ontological and hence, the ready-to-hand is prior to the present-at-hand. Furthermore, only in the event of 'breakdown' when human beings become (come-forth-as) Cartesian subjects, do beings presence as occurrent, that is, as objects with determinate, context-free properties. (Elstob (1984), however, argues for the context-sensitivity of properties). Dreyfus (1991) maintains that Heidegger makes three important points with respect to the Being of the present-at-hand (occurrent):

(1) It is necessary to get beyond our practical concerns in order to be able to encounter mere objects. (2) The 'bare facts' related by scientific laws are isolated by a special activity of selective seeing rather than being simple found [hence, a commitment to a hermeneutic realism]. (3) Scientifically relevant 'facts' are not merely removed from their context by selective seeing; they are theory-laden, i.e., recontextualized in a new projection. (p.81) 
This 'selective seeing' is an Enframing (das Gestell) which involves the postulating of ceteris paribus ("all things being equal") conditions made possible by a grounding in the shared 'background' of human practices. As Dreyfus states, "it is only on the background of already taken up practices and equipment that we can doubt the existence of particular objects, and even a whole domain of objects [that is, exclude beings from consideration in a domain of discourse]." (p.248) Enframing makes possible a modern form of techne (artificing), viz. technology, which is characterized by the joining of occurrent parts in systemic wholes. This metaphysical approach to artificing, in which the occurrent as substantial or processual is taken as primal, has its origins in Plato and Aristotle. While the latter upholds the distinction between artifacts and naturals, this distinction is defined in terms of the becoming (or mode of coming into being) of matter associated with each (natural or artifact): "in the case .. of artifacts we make the matter for the work to be done, whilst in the case of natural objects it is there already" (Physics, Book II, ch.I). Aristotle follows Plato in asserting the primacy of form over matter, essence (whatness) over existence (thatness) based on a view of the latter as the actual or what 'factually' is. This position is carried over into the modern context and culminates in the functionalist claim that substrate ontology is irrelevant and phenomena are multiply-realizable; hence, the possibility of "strong" artificiality, whereby the latter is meant functionally (or behaviourally) isomorphic artifactual realizations of natural phenomena. However, Heidegger's originary association of Being with physis (originating, presencing, arising) and his distinguishing of this mode of poiēsis from technē (artificing) makes possible the distinguishing of naturals from artifactuals on the basis of their respective modes of becoming (poiessis). Heidegger's claim that modern artificing is grounded in the Enframing of nature (as object) by the Cartesian ego (or subject) allows naturality to be distinguished from artificiality on the basis of historical (or hermeneutic) relations (ontic and epistemic) between the Cartesian subject and beings (objects):

\begin{tabular}{|l|c|c|c|}
\cline { 3 - 3 } \multicolumn{2}{c|}{} & \multicolumn{2}{|c|}{$\begin{array}{c}\text { ONTICAL STATUS OF OBJECT } \\
\text { WITH RESPECT TO SUBJECT }\end{array}$} \\
\cline { 2 - 4 } & A PRIORI & A POSTERIORI \\
\hline $\begin{array}{l}\text { EPISTEMICAL } \\
\text { STATUS OF OBJECT }\end{array}$ & A PRIORI & $(1)$ & $(2)$ \\
\cline { 2 - 4 } $\begin{array}{l}\text { WITH RESPECT TO } \\
\text { SUBJECT }\end{array}$ & A POSTERIORI & $(3)$ & (4) \\
\hline
\end{tabular}

Table 3 Historically-defined ontic and epistemic subject-object relations.

Ontically a priori beings are found (given) whereas ontically a posteriori beings are made (artificed) by the human subject; epistemically a priori beings are "forwards-interpretable" whereas epistemically a posteriori beings are (only) "backwards-interpretable" by the human subject. It was stated previously that in the case of naturals, the ready-to-hand (equipmental) is prior to the presentat-hand (occurrent). In the case of artifactuals (or artificials), the present-at-hand (occurrent) is prior since this is how beings are encountered during artificing in the Cartesian subject-object mode. However, since the ontological cannot be derived (or emerge) from the ontical, the present-at-hand cannot give rise to the ready-to-hand. Hence, artificiality cannot support being-in-the-world (Dreyfus,91). This holds true for both (2) and (4) in the above scheme (that is, both for symbolic/topdown and connectionist/bottom-up approaches to artificing) since the Being of the substrate in both cases is epistemically a priori and ontically a posteriori, that is, artifactual or present-at-hand and the latter can only give rise to beings of the same ontological kind, viz. occurrent or present-at-hand.

\subsection{Ontical}

In addition to its implications for the ontological project of an 'artifactual-phenomenology', the system of relations described in Table 3 also has implications for the ontical project of an 
'artifactual-causality.' This immediately becomes apparent upon examining the Being of artifacts and naturals under panexperientialism $(\S 8)$. The key insight is expressed by Heidegger (1977) as follows:

scientific representation, for its part, can never decide whether nature, through its objectness, does not rather withdraw itself than bring to appearance the hidden fullness of its coming to presence. Science cannot even ask this question, for, as theory, it has already undertaken to deal with the area circumscribed by objectness. (p.174)

The Being of objects is objective, that is, externally-defined and externally-related; however, given the existence of experiential entities (humans and possibly other higher-order entities), it is simply an existential fact that there are beings whose Being is (at least partially) subjective, that is, (at least partially) internally-defined and internally-related. Since objects cannot give rise to subjects (\$2), any mode of poiēsis involving objective (external) relations between beings and an artificing subject can only lead to the production of objects. Modern technē, viz. Enframing, is a mode of poiessis which takes beings as objective, that is, encounters them as externally-defined (by the Cartesian subject) and externally-related to each other. While panexperientialism allows beings to be re-interpreted as subjects (thereby returning to the original Greek view of subjectivity), it does not alter the relationality involved in modern artificing: artificers can only access the external aspect of beings, an existential fact which follows from the essence of artificing. This point can be clarified as follows: panexperientialism distinguishes between (1) primitive actual occasions (events) and compound individuals which are experiential and (2) aggregates which are not. In artificing, the parts (components) of the whole (artifact) either are aggregates or are viewed as aggregates. In the latter case, compound individuals or societies of events are epistemically-transformed into aggregates, that is, entities defined in terms of external relations (efficient causation), by an act of 'cutting', that is, "selective-seeing" (\$10.1): individual responses (final causation) to incoming efficient causes are ignored and an average or aggregate response is adopted; thus, the "spectrum" of final causation associated with each event is "collapsed" onto a single final cause. (This has the effect of 'closing' the system down such that contingency/intentionality is transformed into necessity/determinism.) This collapse can and does occur in naturals (for example, stones and clouds) at the level of the aggregate; however, in this case it takes the form of a self-collapse, that is, an autopoiettic process. In artifacts, the collapse is allopoietic and either epistemic or ontic. In the latter case, aggregates are produced (artificed) from compound individuals via cutting $_{2}$ and joining ${ }_{2}$ operations; the former involves the dissociation of an actual occasion from its nexus of experiential relations and the latter leads to the emergence of an aggregate in which experience statistically 'cancels out'. Since both operations are carried out by a subject relating to the primitive material objectively (externally), the product is always an aggregate; thus, artifactual-cutting $_{2}$ and artifactual-joining $_{2}$ cannot generate an experiential nexus. However, natural-cutting ${ }_{2}$ and natural-joining ${ }_{2}$ can support the emergence of compound individuals; this possibility follows from the essence of panexperientialism itself and is demonstrated by the existence of higher-order experiential entities. Moreover, the emergence of compound individuals from aggregates via natural-cutting ${ }_{2}$ and natural-joining ${ }_{2}$ operations is also supported. However, this (logically) necessitates self-re-organization of the aggregate such that its primal components (which are experiential) are able to manifest their subjectivity (experience and final causality) non-aggregatively, that is, in the formation of an experiential nexus; clearly this can only occur naturally in a "suitable" context. It follows, therefore, according to Birch (1994), that

to attempt to make [an experiential artifact] by building up a hierarchy of compound entities that think and feel would [necessarily] be to attempt to repeat evolution from scratch. (p.8)

This is because concresences (compound individuals) are context-sensitive and internally-related and, as Heraclitus maintained, the world of the present, although more like the world of the past than unlike it, is never identical to the latter. Thus, in artifacts, where re-configuration is objectively specified in terms of determinate, context-free external relations and thereby determined - or rendered deterministic - by the artificing subject, the transformation of an aggregate into a compound individual is impossible since although cutting $_{2}$ and joining ${ }_{2}$ can occur, it is necessarily an objective 


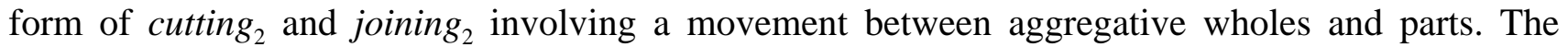
ontical distinction between artificiality and naturality (that is, artifacts and nature respectively) is summarized in the following statement due to Farleigh (1996):

\begin{abstract}
the primary function of a machine can be described in terms of the external relations of the parts which are assumed to be 'simply located'. One set of external relations is as good as any other, and hence the function of one machine can be modeled on another. The function of an organism on the other hand is constituted by both the internal and the external relations between events. Each event is not simply located, is unique to its history and is hence, highly context-dependent. The procedure, then, of attempting to map an organism onto a machine can only be a process of abstraction and hence such a mapping would be done with a loss of information and the two would not be functionally equivalent. The adherents of 'strong AI' [artificial intelligence] and 'strong AL' [artificial life] commit the simple, but major, fallacy of confusing the abstract with the concrete. (p.17)
\end{abstract}

\title{
11. SUMMARY
}

The 'questioning' in this paper assumed the following form: first, a number of problems associated with the notion of emergence were listed and the mind-body or category problem was identified as fundamental; second, a conflict was identified between emergentism and the ex nihilo maxims. It was argued that conventional (that is, materialistic) emergentism cannot solve the category problem due to (1) a commitment to an objectivist and monist ontology (metaphysics) and (2) a classical interpretation of the maxims in which nothing is equated with void. In preparation for a rethinking (and possible rehabilitation) of the notion of emergence, the question of Being, as understood in Heideggerian ontology, was briefly examined. This provided the basis upon which to formulate, in outline, a hermeneutic theory of emergence and, consistent with the new view, an ontical (causal) solution to the category problem grounded in panexperientialism was presented. The ex nihilo maxims were reinterpreted on the new theory and found to be consistent with emergentism as understood in its extended sense. Finally, the ontological (phenomenological) and ontical (causal) problems associated with a shift to the new interpretation of emergence and the adoption of a panexperientialist ontology were briefly considered. An implicit argument for an authentically (that is, recognizably) anthropocentric view of technology (artificing) was made; in short, although we can know (in the sense of "make intelligible"), we cannot always $d o$. Ontology does not entail technology (Ali,97).

\section{REFERENCES}

Ali, S.M., Zimmer, R.M. (1996). Beyond Substance and Process: A New Framework for Emergence. To be published by MIT Press.

Ali, S.M. (1997). Towards an Anthropocentric Computationalism: Ontological and Epistemological Issues in the Evaluation of Computationalism as the Metaphysical Basis of a Unifying Framework of Emergent Artificiality. Ph.D Thesis. Brunel University, England. (Forthcoming)

Ayala, F. (1985). Reduction in Biology: A Recent Challenge. In Evolution at a Crossroads: The New Biology and the New Philosophy of Science. Edited by D.J.Depew and B.H.Weber. MIT Press, Cambridge, MA, pp.65-79.

Baas, N. (1993). Emergence, Hierarchies and Hyperstructures. In Artificial Life III. Edited by C.G.Langton. Santa Fe Institute Studies in the Sciences of Complexity, volume 17, Addison-Wesley, Reading, MA, pp.515-537.

Birch, C. (1994). Why I became a Panexperientialist. (Unpublished manuscript), pp.1-12.

Bunge, M. (1969). Metaphysics, Epistemology and Methodology of Levels. In Hierarchical Structures. Edited by L.L.Whyte, A.G.Wilson, D.Wilson. American Elsevier Publishing Company, Inc., New 
York, pp.17-28.

Bunge, M. (1977). Treatise on Basic Philosophy, Vol.3, Ontology I: The Furniture of the World. D.Reidel, Dordrecht, Holland.

Cariani, P. (1989). On the Design of Devices with Emergent Semantic Functions. Ph.D Thesis. State University of New York, Binghampton.

Cariani, P. (1991). Emergence and Artificial Life. In Artificial Life II. Edited by C.G.Langton, C.Taylor, J.D.Farmer, S.Rasmussen. Santa Fe Institute Studies in the Sciences of Complexity, volume 10, Addison-Wesley, Reading, MA, pp.775-797.

Churchland, P. (1985). Reduction, qualia, and the direct introspection of brain states. Journal of Philosophy 82, pp.8-28.

Collingwood, R.G. (1945). The Idea of Nature. Oxford University Press, Oxford.

Crutchfield, J.P. (1994). Is Anything Ever New ? Considering Emergence. SFI 94-03-011, pp.1-15.

Darley, V. (1994). Emergent Phenomena and Complexity. In Artificial Life IV. Edited by R.A.Brooks, P.Maes. MIT Press, Cambridge, MA, pp.411-416.

Dreyfus, H. (1991). Being-in-the-World: A Commentary on Heidegger's Being and Time, Division I. MIT Press, Cambridge, MA.

Elstob, C.M. (1984). Emergentism and Mind. Cybernetics and Systems Research 2. Edited by R.Trappl. North-Holland, pp.83-88.

Farleigh, P. (1996). An Event-Based Cognitive Science. (Unpublished manuscript), pp.1-18.

Farleigh, P. (1997). Whitehead's Even More Dangerous Idea. (Unpublished manuscript), pp.1-6.

Griffin, D.R. (1988). The Reenchantment of Science. SUNY Press.

Griffin, D.R. (1997). Panexperientialist Physicalism and The Mind-Body Problem. Journal of Consciousness Studies (pre-print), pp.1-20.

Harth, E. (1993). The Creative Loop: How the Brain Makes a Mind. Addison-Wesley, Reading, MA. Heidegger, M. (1959). An Introduction to Metaphysics. Yale University Press, NY.

Heidegger, M. (1973). The End of Philosophy. Introduction and translation by J.Stambaugh. Harper \& Row, NY.

Heidegger, M. (1977). The Question Concerning Technology and Other Essays. Introduction and translation by W.H.Lovitt. Harper \& Row, NY.

Heidegger, M. (1993). What is Metaphysics ? In Martin Heidegger: Basic Writings. Edited by D.F.Krell. Routledge, London, pp.89-110.

Kenyon, F. (1941). The Myth of The Mind. Watts \& Co., London. 
Langton, C.G. (1989). Artificial Life. In Artificial Life. Edited by C.G.Langton. Santa Fe Institute Studies in the Sciences of Complexity, volume VI, Addison-Wesley, Reading, MA, pp.1-47.

Mayr, E. (1982). The Growth of Biological Thought. Harvard University Press.

Nagel, E. (1961). The Structure of Science. Routledge \& Kegan Paul, London.

Nagel, T. (1979). Mortal Questions. Cambridge University Press, London.

Nagel, T. (1986). The View From Nowhere. Oxford University Press, NY.

Polanyi, M. (1967). The Tacit Dimension. Routledge \& Kegan Paul, London.

Prigogine, I., Stengers, I. (1984). Order out of Chaos. Heinemann, London.

Rosen, R. (1977). Complexity as a system property. International Journal of General Systems 3, pp.227-232.

Rosen, R. (1985). Anticipatory Systems. Pergamon Press, NY.

Scott, A.C. (1995). Stairway to The Mind. Springer-Verlag, Berlin.

Searle, J.R. (1980). Minds, Brains and Programs. Behavioural and Brain Sciences 3, pp.417-424.

Searle, J.R. (1992). The Rediscovery of The Mind. MIT Press, Cambridge, MA.

Spencer-Brown, G. (1969). Laws of Form. George Allen \& Unwin Ltd., London.

Sperry, R.W. (1976). Changing concepts of consciousness and free will. Perspectives in Biology and Medicine, 20, pp,9-19.

Tallis, R. (1994). Psycho-Electronics. Ferrington, London. 